\title{
BEBERAPA ASPEK BIOLOGI DAN PRODUKSI HIU PAHITAN (Alopias superciliosus) DI PERAIRAN SELATAN JAWA TENGAH
}

\author{
Several Aspects of Bigeye Thresher Shark (Alopias suerciliosus) Biological and Production \\ in Southern Sea of Central Java
}

\section{Lulu Anjayanti, Abdul Ghofar*) dan Anhar Solichin}

Program Studi Manajemen Sumberdaya Perairan, Departemen Sumberdaya Akuatik

Fakultas Perikanan dan Ilmu Kelautan, Universitas Diponegoro

J1. Prof. Soedarto, SH, Tembalang, Semarang, Jawa Tengah - 50275, Telp/Fax. +6224 7474698

Email : luluanjayanti@gmail.com

\begin{abstract}
ABSTRAK
Hiu pahitan (Alopias superciliosus) merupakan salah satu spesies hiu yang terdapat di perairan selatan Jawa Tengah. Di Indonesia umumnya hewan ini sering tertangkap dengan alat tangkap rawai (longline). Penelitian ini bertujuan untuk mengetahui struktur ukuran, $\mathrm{Lc}_{50 \%}$, hubungan panjang berat, faktor kondisi, nisbah kelamin dan perkembangan produksi A. superciliosus di perairan selatan Jawa Tengah. Penelitian ini menggunakan metode deskriptif dan pengambilan sampel menggunakan metode simple sensus sampling yaitu pengambilan sample secara keseluruhan. Data yang digunakan adalah data panjang cagak, berat dan panjang klasper A. superciliosus. Dari hasil penelitian, diperoleh sampel A. superciliosus sebanyak 431 individu, terdiri dari 154 jantan dan 277 betina. Ukuran A. superciliosus yang didapatkan berkisar dari $92-211 \mathrm{~cm}$. Meskipun hampir semua ukuran kelas diwakili pada kedua jenis kelamin (jantan dan betina), selang ukuran panjang $150-159 \mathrm{~cm}$ adalah kelas dengan jumlah tangkapan tertinggi, dan hasil tangkapan terendah pada ukuran kelas terkecil dan ukuran kelas terbesar. Ukuran rata-rata tertangkap ( $\mathrm{L}_{50 \%}$ ) A. superciliosus jantan adalah $154 \mathrm{~cm}$ dan betina adalah $147 \mathrm{~cm}$. Hubungan panjang berat $A$. superciliosus diperoleh persamaan $\mathrm{W}=$ $0,000004 \mathrm{FL}^{3,239}$. Hal tersebut menunjukkan bahwa sifat pertumbuhan dari A. superciliosus adalah allometrik positif yang berarti pertumbuhan berat lebih cepat dari pertumbuhan panjangnya. Nilai faktor kondisi A. superciliosus diperoleh sebesar 1,066 yang berarti $A$. superciliosus memiliki badan yang kurang pipih. Nisbah kelamin antara jantan dan betina tidak seimbang yaitu $1: 1,8$. Perkembangan produksi $A$. superciliosus berdasarkan data sekunder selama enam tahun terakhir berfluktuatif. Puncak hasil tangkapan mengalami pergeseran, ada kecenderungan puncak hasil tangkapan terjadi pada bulan April - September.
\end{abstract}

Kata kunci : Hiu pahitan; aspek biologi; produksi; Jawa Tengah

\section{ABSTRACT}

Bigeye Thresher Shark (Alopias superciliosus) are one of the species of shark found in the southern sea of Central Java. In Indonesia many of these animals are often caught by longline fishing gear. This study aims to determine the size of the structure, Lc $50 \%$, weight-length relationship, condition factor, sex ratio and development of production A. superciliosus in southern sea of Central Java. This study used a descriptive method and sampling using simple methods census sampling is the taking of the sample as a whole. The data used is data forked length, weight and clasper length of A. superciliosus. From the research results, obtained samples of A. superciliosus as many as 431 people, consisting of 154 males and 277 females. The size of A. superciliosus obtained ranged from $92-211 \mathrm{~cm}$. Although virtually all size classes represented in both sexes (males and females), in the range of sizes $150-159 \mathrm{~cm}$ is the class with the highest number of catches, with very few specimens in the smallest and largest size classes. The average size caught (Lc50\%) A. superciliosus male is $154 \mathrm{~cm}$ and female is $147 \mathrm{~cm}$. A. superciliosus length relationship weight equation $W=$ 0,000004FL ${ }^{3,239}$. It shows that the growth properties of A. superciliosus is a significant positive allometric weight growth faster than the growth in length. A. superciliosus condition factor value obtained for 1,066 which means A. superciliosus have a less flat body. Sex ratio between males and females are not balanced at $1: 1.8$. Developments A. superciliosus based secondary data for the last six years had been fluctuating. The highlight of the catch-shifted, there is a tendency to peak catches occurred in April-September.

Keywords : Bigeye Thresher Shark; biological aspect; production; Central Java *) Penulis penanggungjawab 


\section{PENDAHULUAN}

Perairan selatan Jawa Tengah berhubungan langsung dengan Samudera Hindia. Perairan tersebut memiliki potensi sumberdaya laut yang sangat beragam, salah satunya adalah hiu atau cucut. Sumberdaya perikanan hiu merupakan salah satu komoditas perikanan yang cukup diperhitungkan dalam dekade terakhir. Hal ini dikarenakan permintaan sirip yang tinggi dipasaran internasional. Keragaman jenis hiu yang tinggi sebanyak 116 jenis, maka kondisi tersebut menunjukkan bahwa hampir seluruh jenis hiu yang bernilai ekonomis telah dihadapkan pada ancaman kelangkaan. Berbagai jenis hiu yang tertangkap di Perairan Indonesia, Alopias superciliosus merupakan spesies hiu dari Famili Alopiidae yang bernilai ekonomis tinggi untuk diperdagangkan siripnya di pasaran nasional maupun internasional, karena umumnya hiu tersebut berukuran besar (Fahmi dan Dharmadi, 2013).

Hiu merupakan hewan predator puncak di dalam rantai makanan. Secara alamiah, hiu tidak memiliki predator yang harus dihindari, sehingga dalam siklus hidup hiu tidak mengembangkan strategi khusus untuk melindungi diri dari pemangsa (Fahmi dan Dharmadi, 2013). Hilangnya spesies-spesies predator tingkat atas (apex species) yang mempunyai peran penting dalam jaring-jaring makanan dapat menyebabkan perubahan ekologi yang sangat signifikan. Karakteristik yang dimiliki hiu berbeda dengan ikan bertulang sejati yaitu fekunditas rendah, pertumbuhan lambat, resiko kematian yang tinggi pada semua tingkat umur (Camhi et al., 1998).

Penelitian yang dilakukan oleh Setiawan dan Agung (2015), di PPS Cilacap tercatat sedikitnya 28 jenis hiu yang tertangkap. A. superciliosus (17,45\%) diketahui urutan ketiga dominan tertangkap yang didaratkan di PPS Cilacap setelah A. pelagicus (20,33\%) dan Carcharinus sorrah (20,19\%). Sedangkan A. superciliosus yang ada di Indonesia sudah masuk kedalam kategori rawan (vurnerable) terhadap kepunahan menurut red list IUCN (Fahmi dan Dharmadi, 2013). Permintaan A. superciliosus yang semakin besar dikhawatirkan pada penangkapan berlebih yang akan berdampak pada penurunan jumlah stok A. superciliosus bahkan dapat berakibat pada kepunahan spesies tersebut apabila tidak adanya upaya pengelolaan. Sedangkan penangkapan hiu dilakukan secara terus-menerus sepanjang tahun tanpa adanya aturan dan kebijakan yang jelas dan tegas. Selain itu, terbatasnya informasi-informasi ilmiah dan penelitian khusus $A$. superciliosus di Indonesia. Berdasarkan hal tersebut maka penelitian ini penting dilakukan untuk tindak lanjut dalam menjaga keseimbangan ekosistem dan juga mengetahui informasi ilmiah lebih dalam berupa monitoring dan pendataan A. superciliosus.

\section{MATERI DAN METODE PENELITIAN}

\section{A. Materi Penelitian}

Peralatan yang digunakan dalam penelitian ini adalah roll meter digunakan untuk mengukur panjang cagak $A$. superciliosus dengan satuan $\mathrm{cm}$, timbangan untuk mengukur berat $A$. superciliosus, alat tulis dan kamera. Bahan yang digunakan adalah sampel hiu pahitan (A. superciliosus) yang ditangkap di perairan selatan Jawa Tengah yang didaratkan di Pelabuhan Perikanan Samudera (PPS) Cilacap.

\section{B. Metode Penelitian}

Metode penelitian yang digunakan dalam penelitian ini adalah metode deskriptif (Suryana, 2010). Pengambilan sampel dilakukan dengan metode sample sensus sampling yaitu pengambilan sampel secara keseluruhan (Rochmatin, 2014). Pengambilan sampel dilakukan ketika ada pendaratan kapal. Dalam membedakan jenis kelamin A. superciliosus jantan dan betina, pada A. superciliosus jantan terdapat dua buah klasper yang terdapat pada bagian sirip perut. Data yang digunakan diperoleh dari data primer dan sekunder. Data primer merupakan data yang diperoleh dari pengamatan langsung dilapangan yang meliputi data berat, panjang cagak (fork length) dan panjang klasper, sedangkan data sekunder merupakan data yang diperoleh dari PPS Cilacap yang berupa data time series produksi A. superciliosus selama enam tahun terkahir dari tahun $2011-2016$.

\section{Metode Perhitungan}

\section{Struktur ukuran}

Penentuan struktur ukuran panjang hasil tangkapan hiu menggunakan data panjang cagak A. superciliosus. Adapun tahapan untuk menentukannya adalah sebagai berikut:

1. Menentukan jangkauan kelas $(\mathrm{J})$ dengan rumus:

2. Menentukan jumlah kelas interval (K) : Jangkauan $=$ data terbesar - data terkecil

3. Menentukan panjang interval kelas (C) :

$$
\mathrm{K}=1+3,3 \log \mathrm{n}
$$

$$
\mathrm{C}=\text { Jangkauan / Jumlah kelas interval }
$$

4. Menentukan nilai tengah untuk setiap kelas interval.

5. Menentukan frekuensi atau jumlah untuk setiap kelas interval.

6. Menjumlahkan frekuensi dan memeriksa apakah hasilnya sama dengan banyaknya total data panjangnya.

\section{Ukuran rata-rata panjang pertama kali tertangkap ( $\left.\mathbf{L c}_{50 \%}\right)$}

Penentuan pendugaan ukuran rata-rata panjang pertama kali tertangkap ( $\mathrm{Lc}$ atau $\mathrm{L}_{50 \%}$ ) diperoleh dengan mencari nilai rata-rata $50 \%$, yang mencerminkan ukuran tengah ikan tertangkap yaitu dengan memplotkan persentase frekuensi kumulatif ikan yang tertangkap dengan ukuran fork length (Saputra, 2008). Metode yang dilakukan dalam penentuan ukuran rata-rata tertangkap A. superciliosus dengan cara sebagai berikut:

1. Membuat kelas panjang A. superciliosus dan menghitung frekuensi setiap kelas panjang;

2. Menghitung persentase frekuensi masing-masing kelas panjang; 
3. Menghitung persentase kumulatif dari frekuensi masing-masing kelas panjang;

4. Nilai $\mathrm{Lc}_{50 \%}$ diperoleh dengan memplotkan persentase frekuensi kumulatif $A$. superciliosus yang tertangkap dengan ukuran panjang cagak.

\section{Faktor kondisi}

Effendie (2002), faktor kondisi dapat dihitung dengan menggunakan rumus menurut sebagai berikut:

Nisbah kelamin

$$
\begin{array}{ll}
\mathrm{Kn} & =\text { Faktor Kondisi } \\
\mathrm{W} & =\text { Berat Rata-Rata }(\mathrm{kg}) \\
\mathrm{L} & =\text { Panjang Cagak Rata-Rata }(\mathrm{cm}) \\
\mathrm{a} & =\text { Intercept } \\
\mathrm{b} & =\text { Slope }
\end{array}
$$
berikut:

Menurut Saputra et al. (2009), persamaan yang digunakan untuk menghitung nisbah kelamin adalah sebagai

$\begin{array}{lll}\text { Keterangan: } & \mathrm{NK} & \text { : Nisbah kelamin } \\ & \mathrm{N}_{\mathrm{bi}} & \text { : Jumlah ikan betina } \\ & \mathrm{N}_{\mathrm{ji}} & \text { : Jumlah ikan jantan }\end{array}$

$$
\mathrm{NK}=\frac{\mathrm{N}_{\mathrm{bi}}}{\mathrm{N}_{\mathrm{ji}}}
$$

Analisis Data

Analisis hubungan panjang berat

Menurut Effendie (2002), hubungan panjang berat dapat di analisis dengan rumus persamaan:

Keterangan : $\quad \mathrm{W}=$ berat $(\mathrm{kg})$,

$$
\mathrm{W}=\mathrm{aL}^{\mathrm{b}}
$$

$$
\begin{aligned}
& \mathrm{L}=\text { panjang cagak }(\mathrm{cm}), \\
& \mathrm{a}=\text { intercept } \\
& \mathrm{b}=\text { slope }
\end{aligned}
$$

Nilai $b$ sebagai penduga hubungan antara panjang dan berat dengan kriteria:

- $\quad b=3$, pola pertumbuhan isometrik (pertambahan berat seimbang dengan pertambahan panjang).

- $\quad b>3$, pola pertumbuhan alometrik positif (pertambahan berat lebih cepat dari pertambahaan panjang).

- $\quad \mathrm{b}<3$, pola pertumbuhan alometrik negatif (pertambahan panjang lebih cepat dari pertambahan berat).

Untuk mengetahui nilai $b=3$ atau $b \neq 3$, hipotesis yang digunakan adalah sebagai berikut:

Ho: Pertambahan panjang seimbang dengan pertambahan berat atau $b=3$.

$\mathrm{H}_{1}$ : Pertambahan panjang tidak seimbang dengan pertambahan berat atau $\mathrm{b} \neq 3$.

Kaidah pengambilan keputusan dengan uji-t dari hipotesis tersebut secara matematis rumusnya sebagai berikut:

$$
\begin{aligned}
\mathrm{t}=\frac{3-\mathrm{b}}{\mathrm{Sb}} & \leq \alpha / 2 ;(\mathrm{n}-1), \text { terima Ho } \\
& >\mathrm{T} \alpha / 2 ;(\mathrm{n}-1), \text { tolak Ho }
\end{aligned}
$$

t hitung $>\mathrm{t}$ tabel $\longrightarrow$ tolak Ho, artinya pertumbuhan ikan allometrik

$\mathrm{t}$ hitung $\leq \mathrm{t}$ tabel $\longrightarrow$ terima Ho, artinya pertumbuhan ikan isometrik

Analisis uji Chi Square

Pengujian perbandingan jenis kelamin dilakukan dengan uji Chi Square yaitu (Nasir, 1983):

Keterangan: $\quad \mathrm{X}^{2}=$ Chi Square

$$
X^{2}=\sum_{i=1}^{k} \frac{\left(O_{1}-E_{i}\right)^{2}}{E_{i}}
$$

Hipotesis:

$\mathrm{O}_{1}=$ Frekuensi yang diobservasi

$\mathrm{E}_{1}=$ Frekuensi yang diharapkan

$\mathrm{X}^{2}$ hitung $>\mathrm{X}^{2}$ tabel $\longrightarrow$ tolak Ho

$\mathrm{X}^{2}$ hitung $\leq \mathrm{X}^{2}$ tabel $\longrightarrow$ terima Ho

Ho : jumlah jantan $=$ jumlah betina, rasio kelamin dinyatakan seimbang

$\mathrm{H}_{1}$ : jumlah betina $\neq$ jumlah betina, rasio kelamin dinyatakan tidak seimbang.

\section{HASIL DAN PEMBAHASAN}

\section{Struktur Ukuran}

Selama penelitian sampel hiu A. superciliosus di perairan selatan Jawa Tengah pada bulan Agustus - September 2016 sebanyak 431 individu, terdiri dari 154 jantan dan 277 betina. Ukuran A. superciliosus yang didapatkan berkisar dari $92-211 \mathrm{~cm}$, dengan ukuran terpanjang pada jantan adalah $196 \mathrm{~cm}$ dan betina $211 \mathrm{~cm}$. Ukuran yang tertangkap didominasi pada selang ukuran $150-159 \mathrm{~cm}$ sebanyak 91 individu. Ukuran panjang A. superciliosus dibedakan 
berdasarkan jenis kelamin. Ukuran A. superciliosus jantan yang didapatkan berkisar dari 94 - $196 \mathrm{~cm}$, ukuran yang tertangkap didominasi pada selang ukuran $150-159 \mathrm{~cm}$ sebanyak 35 individu. Pada A. superciliosus betina, yang didapatkan berkisar $92-211 \mathrm{~cm}$, ukuran yang tertangkap didominasi pada selang ukuran 150 - 159 cm sebanyak 56 individu. Meskipun hampir semua ukuran kelas diwakili pada kedua jenis kelamin, selang ukuran panjang $150-159 \mathrm{~cm}$ adalah kelas dengan jumlah tangkapan tertinggi. Hasil tangkapan terendah pada ukuran kelas terkecil dan ukuran kelas terbesar. Ukuran A. superciliosus jantan dan betina berdasarkan hasil tangkapan kapal di perairan selatan Jawa Tengah tersaji berurutan pada Gambar 1, 2 dan 3.

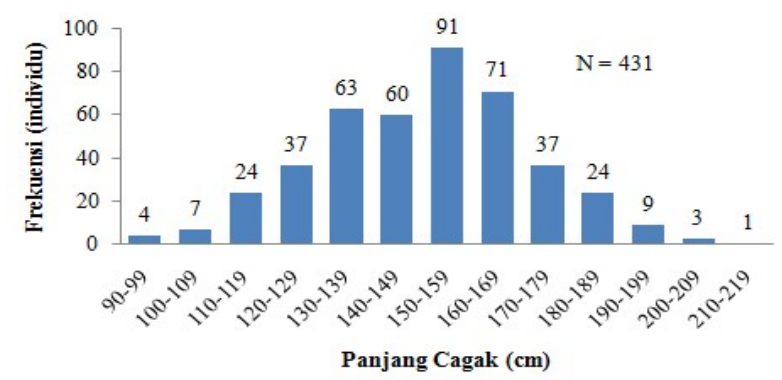

Gambar 1. Distribusi Frekuensi Panjang A. superciliosus selama Penelitian

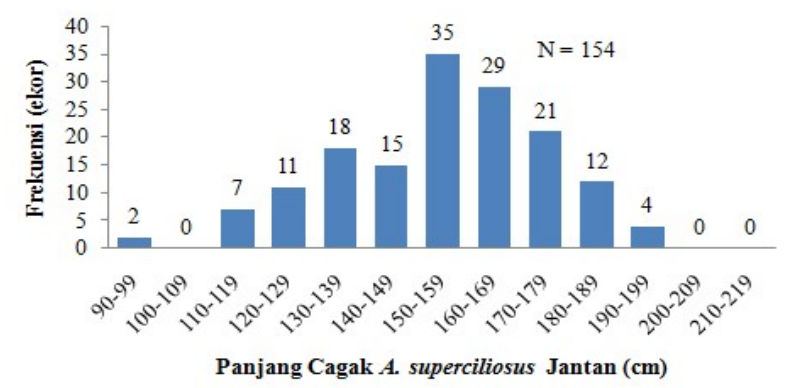

Gambar 2. Distribusi Frekuensi Panjang A. superciliosus Jantan selama Penelitian

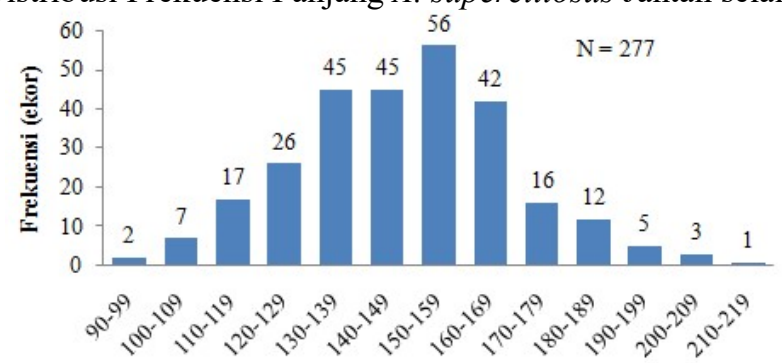

Panjang Cagak A. superciliosus Betina (cm)

Gambar 3. Distribusi Frekuensi Panjang A. superciliosus Betina selama Penelitian

\section{Ukuran Rata-Rata Panjang Pertama Kali Tertangkap (L50\%)}

Ukuran pertama kali tertangkap ( $\left.\mathrm{L}_{50 \%}\right)$ A. superciliosus gabungan (jantan dan betina) adalah $148 \mathrm{~cm}$. $\mathrm{L}_{50 \%} \mathrm{jantan}$ adalah $154 \mathrm{~cm}$ dan betina $147 \mathrm{~cm}$. Grafik $\mathrm{L}_{50 \%}$ A. superciliosus gabungan, jantan dan betina secara berurutan dapat dilihat pada Gambar 4, 5, dan 6 .



Gambar 4. Ukuran Pertama Kali Tertangkap $\left(\mathrm{L}_{50 \%}\right)$ A. superciliosus selama Penelitia 


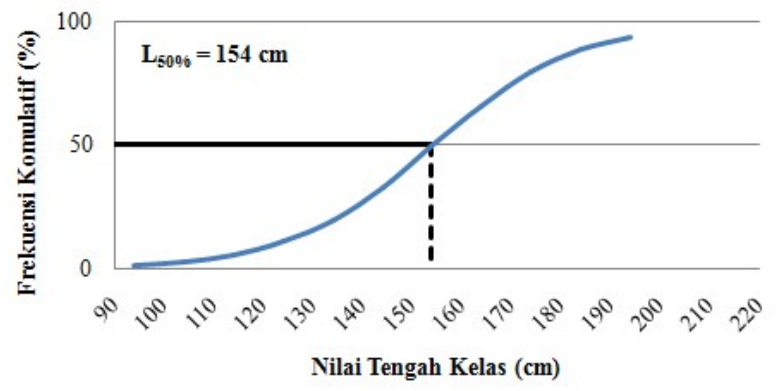

Gambar 5. Ukuran Pertama Kali Tertangkap ( $\left.\mathrm{L}_{50 \%}\right)$ A. superciliosus Jantan selama Penelitian

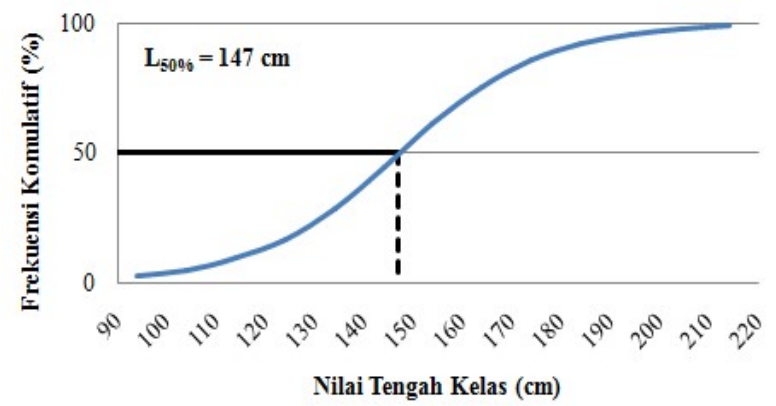

Gambar 6. Ukuran Pertama Kali Tertangkap $\left(\mathrm{L}_{50 \%}\right)$ A. superciliosus Betina selama Penelitian

Berdasarkan ketiga perhitungan ukuran pertama kali tertangkap di atas didapatkan nilai $\mathrm{L}_{50 \%}>1 / 2 \mathrm{~L} \infty$. Apabila Lc dikaitkan dengan Lo maka ukuran A. superciliosus yang tertangkap masih layak untuk ditangkap.

\section{Hubungan Panjang Berat}

Selama penelitian, sampel A. superciliosus yang diperoleh sebanyak 431 individu memiliki kisaran panjang 92 $211 \mathrm{~cm}$ dan kisaran berat $7-138 \mathrm{~kg}$. Adapun grafik hubungan panjang berat A. superciliosus gabungan, jantan dan betina secara berurutan selama penelitian dapat dilihat pada Gambar 7, 8 dan 9.

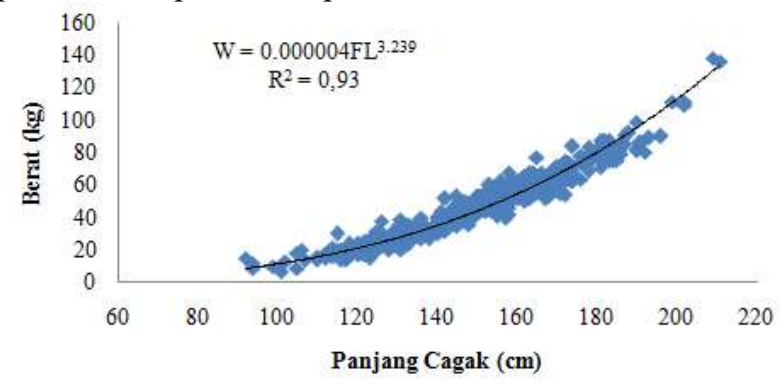

Gambar 7. Hubungan Panjang Berat A. superciliosus selama Penelitian

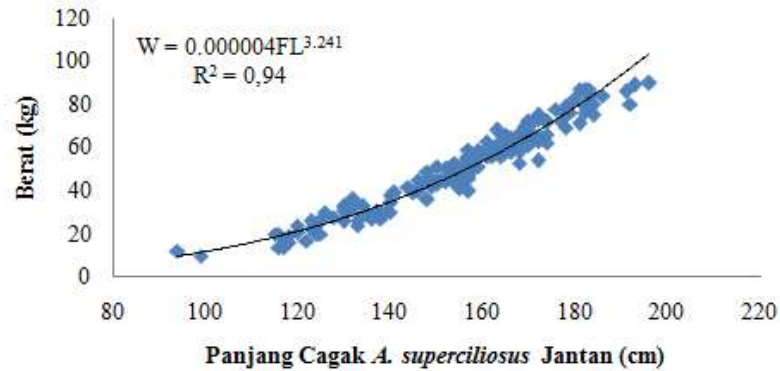

Gambar 8. Hubungan Panjang Berat A. superciliosus Jantan selama Penelitian

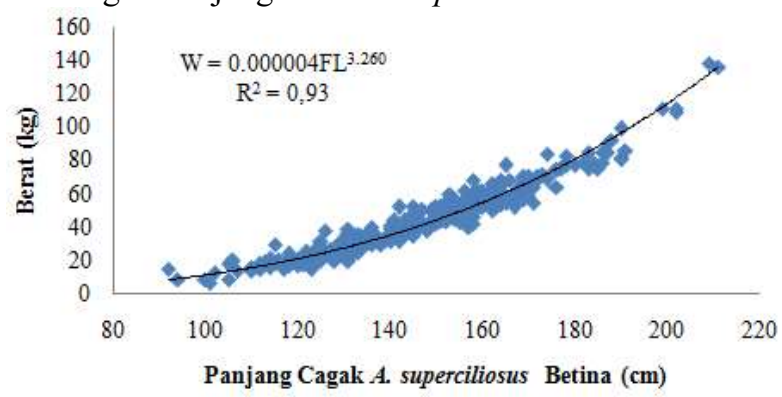

Gambar 9. Hubungan Panjang Berat A. superciliosus Betina selama Penelitian 
Berdasarkan dari ketiga perhitungan di atas, hasil pengujian terhadap nilai t diperoleh angka $b>3$, menunjukkan bahwa hubungan panjang berat $A$. superciliosus yang tertangkap memiliki pola pertumbuhan yang sama, yaitu allometrik positif dengan pertumbuhan berat lebih cepat dari pertumbuhan panjangnya.

\section{Faktor Kondisi}

Angka faktor kondisi A. superciliosus selama penelitian tertera pada Tabel 1.

Tabel 1. Angka Faktor Kondisi A. superciliosus Selama Penelitian

\begin{tabular}{cccccc}
\hline $\begin{array}{c}\text { Jumlah } \\
\text { sampel (n) }\end{array}$ & Intercept (a) & Slope (b) & $\begin{array}{c}\text { Panjang } \\
\text { Rata-rata (L) (cm) }\end{array}$ & $\begin{array}{c}\text { Berat rata-rata } \\
\text { (W) (kg) }\end{array}$ & $\mathbf{K n}_{\mathbf{k}} \mathbf{W} / \mathbf{a L} \mathbf{L}^{\mathbf{b}}$ \\
\hline 431 & 0,000004 & 3,239 & 149,73 & 47,38 & 1,066 \\
\hline
\end{tabular}

Sumber: Hasil Penelitian, 2016

Angka faktor kondisi yang diperoleh selama penelitian yaitu 1,066 diman angka tersebut berkisar antara $1-3$, yang berarti $A$. Superciliosus memiliki badan yang kurang pipih.

\section{Nisbah Kelamin}

Nisbah kelamin yang diperoleh selama penelitian tertera pada Tabel 2.

Tabel 2. Perbandingan Jenis Kelamin A. superciliosus selama Penelitian

\begin{tabular}{ccc}
\hline Jenis Kelamin & Jumlah & Nisbah Kelamin (\%) \\
\hline Jantan & 154 & 36 \\
Betina & 277 & 64 \\
Total & 431 & \\
\hline
\end{tabular}

Sumber: Hasil Penelitian, 2016

Hasil pengujian terhadap Chi-Square atau Chi Kuadrat diperoleh $\mathrm{X}^{2}$ hitung $=35,02$ dan $\mathrm{X}^{2}$ tabel Chi-square pada tingkat kepercayaan 95\% adalah 3,811 $\left(\mathrm{X}^{2}\right.$ tabel $\left._{(0,05)}=3,811\right)$. Dengan nilai tersebut maka $\mathrm{X}^{2}$ hitung $>\mathrm{X}^{2}$ tabel $(35,02>$ 3,811), yang berarti $\mathrm{H}_{\mathrm{o}}$ ditolak. Hal ini menunjukkan bahwa perbandingan jenis kelamin jantan dan betina berbeda nyata atau dalam keadaan tidak seimbang $(1: 1,8 ; 36 \%: 64 \%)$.

\section{Produksi $A$. superciliosus}

Hasil pengamatan dari jumlah produksi total A. superciliosus yang didaratkan di PPS Cilacap selama penelitian pada bulan Agustus - September 2016 disajikan pada Tabel 3.

Tabel 3. Produksi A. superciliosus Selama Penelitian

\begin{tabular}{ccc}
\hline Bulan & Produksi (kg) & Persentase (\%) \\
\hline Agustus & 7.354 & 36 \\
September & 13.065 & 64 \\
\hline Total & 20.419 & 100 \\
\hline
\end{tabular}

Sumber : Data Penelitian 2016

Pengambilan sampel $A$. superciliosus dilakukan setiap hari selama ada bongkar muat kapal yang membawa hasil tangkapan hiu di pelabuhan. Hasil tangkapan A. superciliosus pada dua bulan tersebut berbeda. Hal ini dapat disebabkan oleh beberapa faktor seperti ukuran kapal yang digunakan berkisar antara 17 - 29 GT, lama trip penangkapan yang biasa dilakukan nelayan berkisar antara satu hingga empat minggu. Jumlah trip pada bulan Agustus yaitu empat kali, sedangkan pada bulan September sebanyak enam kali, sehingga hasil produksi pada bulan September lebih banyak dibandingkan dengan bulan Agustus. Selain data yang diperoleh saat berlangsungnya penelitian atau data primer juga terdapat data sekunder yang merupakan pencatatan tahunan (time series) yang dilakukan oleh enumerator di PPS Cilacap. Data sekunder ini meliputi data total produksi A. superciliosus dalam kurun waktu enam tahun terakhir dari tahun 2011 - 2016 dapat dilihat pada Gambar 10.

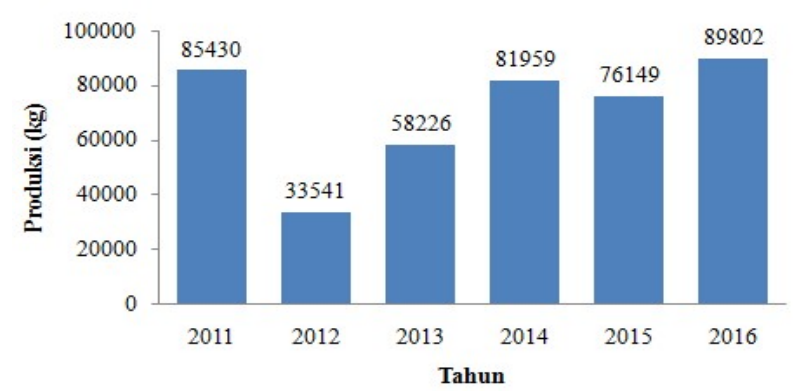

Gambar 10. Produksi A. superciliosus pada Tahun 2011 - 2016

Berdasarkan gambar diatas, total produksi A. superciliosus yang didaratkan yang diperoleh dari data PPS Cilacap selama kurun waktu enam tahun terakhir mengalami naik turun atau berfluktuasi. Dari keenam tahun tersebut, jumlah produksi tahun 2016 sebanyak $89.802 \mathrm{~kg}$, merupakan produksi tertinggi dibandingkan dengan tahun lainnya, sedangkan produksi terendah pada tahun 2012 sebesar $33.541 \mathrm{~kg}$. Produksi hiu yang dihasilkan berdasarkan penangkapan yang dilakukan oleh nelayan dengan menggunakan alat tangkap longline. Berikut (Gambar 11) merupakan jumlah alat tangkap yang digunakan dalam penangkapan hiu A. superciliosus adalah sebagai berikut: 


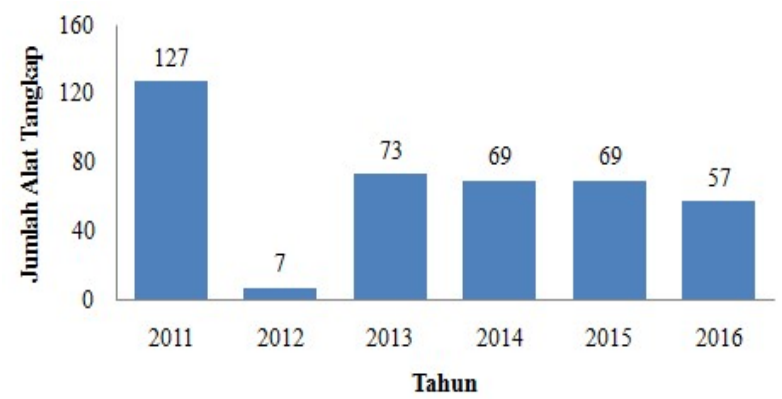

Gambar 11. Jumlah Alat Tangkap pada Tahun 2011 - 2016

Berdasarkan gambar diatas, produksi $A$. superciliosus yang tertangkap selama enam tahun terakhir dengan jumlah alat tangkap tidak sebanding, walaupun produksi $A$. superciliosus tinggi, tidak berarti jumlah alat tangkap yang digunakan pada setiap tahunnya banyak. Hal ini diduga karena pada setiap kali penangkapan memiliki hasil tangkapan yang berbeda pada setiap jumlah dan bobot hiu yang tertangkap dan jumlah armada dan ukuran kapal. Data sekunder produksi A. superciliosus selama enam tahun terakhir juga dapat dilihat produksi pada setiap bulannya. Berikut data sekunder produksi $A$. superciliosus dari tahun 2011 - 2016 pada gambar berikut:
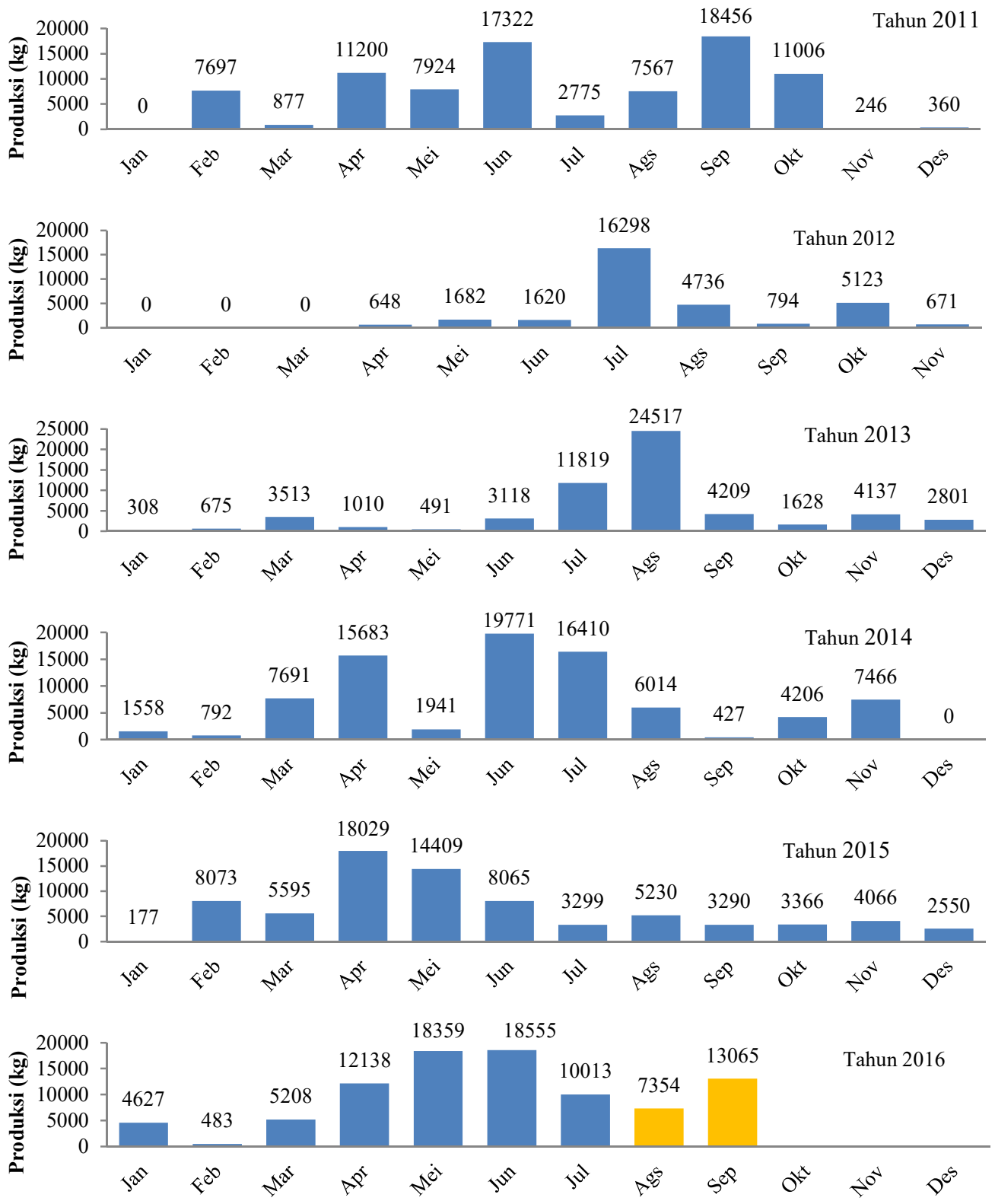

Gambar 12. Produksi A. superciliosus setiap Bulan Berdasarkan Data Sekunder Tahun 2011 - 2016

Dari gambar di atas dapat dilihat bahwa hasil tangkapan A. superciliosus setiap bulan dalam kurun waktu enam tahun terakhir tidak menentu. Warna kuning pada bulan Agustus - September 2016 merupakan data primer yang berasal dari pengamatan langsung selama penelitian. Umumnya aktivitas penangkapan hiu berlangsung sepanjang tahun. Pada bulan tertentu memiliki frekuensi hasil tangkapan tertinggi, namun pada bulan tertentu juga memiliki frekuensi hasil 
tangkapan terendah. Pada tahun 2011 puncak hasil tangkapan pada bulan September, tahun 2012 pada bulan Juli, tahun 2013 pada bulan Agustus, tahun 2014 pada bulan Juni, tahun 2015 pada bulan April dan tahun 2016 pada bulan Juni.

Puncak hasil tangkapan A. superciliosus mengalami pergeseran. Puncak hasil tangkapan terlihat adanya kecenderungan hasil tangkapan pada bulan April - September. Sedangkan pada bulan lainnya hasil tangkapan $A$. superciliosus rendah bahkan tidak terdapat tangkapan $A$. superciliosus. Hal ini dapat disebabkan oleh beberapa faktor seperti perbedaan lama trip dan jumlah kapal penangkapan pada setiap bulannya, biasanya lama trip penangkapan yang dilakukan para nelayan selama satu hingga empat minggu. Selain itu, ukuran kapal yang digunakan untuk penangkapanpun tidak sama, sehingga hasil tangkapannyapun berbeda.

\section{Pembahasan}

Berdasarkan penelitian yang dilakukan pada bulan Agustus - September 2016 diperoleh sampel A. superciliosus sebanyak 431 individu, terdiri dari 154 jantan dan 277 betina. Ukuran A. superciliosus yang didapatkan berkisar dari 92 - $211 \mathrm{~cm}$. Meskipun hampir semua ukuran kelas diwakili pada kedua jenis kelamin (jantan dan betina), selang ukuran panjang 150 - $159 \mathrm{~cm}$ adalah kelas dengan jumlah tangkapan tertinggi, sedangkan hasil tangkapan terendah pada ukuran kelas terkecil dan ukuran kelas terbesar.

Nilai $\mathrm{Lc}_{50 \%}$ jantan lebih besar dari betina. Hal ini dapat dikarena pada saat di alam hiu jantan lebih sulit ditangkap karena pergerakannya lebih cepat dan lincah dibandingkan dengan hiu betina. Nilai $\mathrm{Lc}_{50 \%}$ secara keseluruhan lebih besar dari $1 \frac{1}{2} \mathrm{~L}_{\infty}$. Apabila Lc dikaitkan dengan $\mathrm{L} \infty$ maka ukuran A. superciliosus yang tertangkap masih layak untuk ditangkap, dengan masih layak tertangkapnya A. superciliosus maka diharapkan operasi penangkapan di selatan Pulau Jawa tidak terjadi overfishing.

Ukuran panjang $A$. superciliosus yang tertangkap dari hasil penelitian ini cenderung sama dengan penelitian yang dilakukan sebelumnya oleh Preti et al. (2008), A. superciliosus yang tertangkap pada kisaran ukuran mulai dari $147-230 \mathrm{~cm}$ fork length (FL). Jumlah betina sebanyak 8 ekor dan jantan 17 ekor dan satu specimen jenis kelaminnya tidak ditentukan. Penelitian tentang A. superciliosus juga dilakukan oleh Fernandez et al. (2011), dari 117 total sampel, 73 betina dan 42 jantan serta dua spesimen jenis kelaminnya tidak ditentukan. Ukuran spesimen yang digunakan berkisar dari $101-242 \mathrm{~cm}$, dengan spesimen terpanjang pada jantan adalah $210 \mathrm{~cm}$ dan betina $242 \mathrm{~cm}$. Meskipun hampir semua ukuran kelas diwakili di kedua jenis kelamin, ukuran panjang $150 \mathrm{~cm}$ adalah kelas dengan jumlah tangkapan tertinggi. Hasil tangkapan terendah pada ukuran kelas terkecil dan ukuran kelas terbesar.

Hasil analisis hubungan panjang berat dari ketiga data tersebut menunjukkan bahwa hubungan panjang berat $A$. superciliosus yang tertangkap memiliki pertumbuhan yang sama, yaitu allometrik positif yang berarti pertumbuhan berat lebih cepat dibandingkan dengan pertumbuhan panjang. Hal ini diperkuat oleh Effendie (2002) apabila nilai b lebih besar dari 3 maka pertumbuhan allometrik, yang menunjukkan ikan tersebut montok yaitu pertumbuhan berat lebih cepat dari pertambahan panjangnya.

Hal ini berbeda dengan penelitian yang dilakukan sebelumnya, jenis hiu yang ditelitipun berbeda, namun masih dalam satu genus yang sama. Penelitian yang dilakukan oleh Dharmadi et al. (2012), sampel yang diteliti yaitu hiu tikusan (A. pelagicus), disebutkan bahwa hubungan panjang total dan berat hiu A. pelagicus berdasarkan uji t diperoleh nilai $\mathrm{b}=3$, sehingga hubungan tersebut bersifat isometrik yang menunjukkan pertumbuhan panjang sama dengan pertumbuhan berat. Menurut Jenning et al. (2001), secara umum, nilai "b" dipengaruhi oleh faktor dalam dan luar. Faktor dalam seperti kondisi fisiologis, genetik, jenis kelamin, umur, parasit atau penyakit. Froese (2006), menambahkan faktor luar yaitu berasal dari lingkungan seperti suhu, $\mathrm{pH}$, salinitas dan letak geografis dan juga kondisi biologis seperti perkembangan gonad dan ketersediaan makanan yang ada di daerah tersebut.

Angka faktor kondisi $A$. supeciliosus yang didaratkan di PPS Cilacap yaitu 1,066. Angka tersebut dapat menunjukkan bahwa spesies A. supeciliosus memiliki bentuk kurang pipih. Menurut Effendie (2002), nilai faktor kondisi berkisar $2-4$ berarti badan ikan agak pipih dan jika nilai faktor kondisi berkisar $1-3$, berarti badan ikan kurang pipih. Faktor yang menentukan nilai faktor kondisi yaitu ketersediaan makanan, umur, jenis kelamin, dan kematangan gonad. Hal ini juga diperkuat oleh Effendie (1979), apabila kondisi lingkungan buruk maka akan menyebabkan berkurangnya berat tubuh dan bila kondisi lingkungan baik dan cukup nutrisi maka berat badan akan bertambah. Faktor kondisi dapat dipengaruhi oleh ketersediaan makanan, umur, sex rasio dan tingkat kematangan gonad. Selain itu, Prihatiningsih et al. (2013), perubahan nilai faktor kondisi dapat dipengaruhi oleh pola musim yang terjadi di perairan sehingga suatu organisme perlu beradaptasi terhadap perubahan kondisi lingkungan.

Berdasarkan hasil uji Chi-Square yang dilakukan pada seluruh sampel yang didaratkan di PPS Cilacap maka diperoleh $X^{2}$ hitung $=35,02$ dan tabel Chi-square pada tingkat kepercayaan 95\% adalah 3,811 $\left(X^{2}\right.$ tabel $\left.(0,05)=3,811\right)$. Dengan nilai tersebut maka $\mathrm{X}^{2}$ hitung $>\mathrm{X}^{2}$ tabel $(35,02>3,811)$, yang berarti $\mathrm{H}_{\mathrm{o}}$ ditolak. Hal ini menunjukkan bahwa perbandingan jenis kelamin jantan dan betina berbeda nyata atau dlaam keadaan tidak seimbang $(1: 1,8 ; 36 \%: 64 \%)$. Secara umum, jumlah betina lebih banyak tertangkap dibanding jantan. Hal ini diduga tingginya persentase populasi $A$. superciliosus betina dibandingkan A. superciliosus jantan adalah kondisi alami di alam.

Menurut Wahyuono et al. (1983), apabila jantan dan betina seimbang atau lebih banyak betina dapat diartikan bahwa populasi tersebut masih ideal untuk mempertahankan kelestariannya. Hal ini juga diperkuat oleh Candramila dan Junardi (2006), faktor yang dapat menyebabkan ketidakseimbangan populasi elasmobranchii adalah jumlah betina yang dihasilkan pada satu kali reproduksi lebih banyak. Komposisi jantan dan betina dalam populasi merupakan faktor penting untuk kelestarian populasi. Rasio jantan lebih tinggi dapat mengganggu kelestarian spesies dengan asumsi bahwa peluang jantan untuk melakukan perkawinan dan menghasilkan keturunan akan lebih rendah karena jumlah 
hewan betina yang terdapat dalam populasi tersebut lebih sedikit. Gangguan pada kelestarian populasi ini kemungkinan dapat lebih buruk jika terjadi penangkapan spesies tertentu saja oleh manusia.

Produksi A. superciliosus di perairan selatan Jawa Tengah diperoleh berdasarkan data primer dan juga data sekunder. Berdasarkan data primer yang diperoleh selama penelitian berlangsung pada bulan Agustus - September 2016 produksi yang dihasilkan pada setiap bulannya berbeda dan produksi pada bulan September lebih banyak dibandingkan dengan bulan Agustus. Hal ini dapat terjadi karena beberapa faktor seperti ukuran kapal dan lama trip penangkapan. Adapun ukuran kapal yang digunakan untuk penangkapan hiu berkisar antara 17 - 29 GT. Lama trip penangkapan hiu pada setiap kapal biasanya selama satu hingga empat minggu di laut.

Menurut Candramila dan Junardi (2006), jumlah hasil tangkapan dapat dipengaruhi oleh banyak faktor antara lain besar kecilnya armada dan tipe alat tangkap, lokasi penangkapan, waktu penangkapan dan perilaku ikan yang ditangkap. Hasil tangkapan juga dipengaruhi oleh waktu penangkapan, musim tangkapan biasanya pada bulan Juli dan Agustus. Pada kedua bulan ini frekuensi penangkapan lebih tinggi dibandingkan bulan lainnya.

Produksi A. superciliosus berdasarkan data sekunder pada kurun waktu selama enam tahun terakhir yang diperoleh dari data PPS Cilacap berfluktuasi. Puncak hasil tangkapan A. superciliosus mengalami pergeseran, adanya kecenderungan bahwa puncak hasil tangkapan A. superciliosus terjadi pada bulan April - September, sedangkan pada bulan-bulan tertentu hasil tangkapan $A$. superciliosus rendah bahkan tidak terdapat hasil tangkapan $A$. superciliosus. Hal ini dapat dikarenakan oleh beberapa faktor seperti perbedaan lama trip penangkapan, ukuran kapal dan jumlah kapal. Faktor lain yang juga tidak kalah penting yaitu pencatatan jumlah produksi hiu secara terus-menerus dan akurat. Kurangnya sumberdaya atau tenaga kerja dan juga kedisiplinan merupakan kendala dalam kegiatan enumerasi pada saat di pelabuhan tersebut.

Menurut Fahmi dan Dharmadi (2013) juga menyatakan bahwa hasil tangkapan hiu mencapai puncaknya sekitar bulan Juli - September, sedangkan tangkapan terendah antara bulan November - Januari. Hiu juga dapat tertangkap dengan berbagai tipe alat tangkap baik yang berupa jaring, pancing, maupun tombak. Berdasarkan rentang persentase ketertangkapan hiu sebagai tangkapan sampingan, maka alat tangkap jaring insang (gill net) dan rawai (longline) merupakan alat tangkap yang termasuk dalam kategori beresiko tinggi dalam menangkap hiu.

\section{KESIMPULAN}

Kesimpulan yang dapat diperoleh dari hasil penelitian adalah sebagai berikut:

1. Struktur ukuran $A$. superciliosus yang tertangkap didominasi pada selang ukuran $150-159 \mathrm{~cm}$, sedangkan ukuran paling sedikit pada selang ukuran terkecil dan terbesar. Nilai $\mathrm{Lc}_{50 \%}>1 / 2 \mathrm{~L}_{\infty}$ maka ukuran A. superciliosus yang tertangkap masih layak untuk ditangkap.

2. Analisis hubungan panjang berat menunjukkan pola pertumbuhan allometrik positif. Angka faktor kondisi yaitu 1, 066 yang menunjukkan $A$. superciliosus berukuran kurang pipih. Nisbah kelamin $A$. superciliosus antara jantan dan betina tidak seimbang yaitu $1: 1,8$.

3. Total produksi $A$. superciliosus selama penelitian sebanyak $20.419 \mathrm{~kg}$. Sedangkan perkembangan produksi selama kurun waktu enam tahun terakhir mengalami naik turun. Puncak tangkapan tertinggi cenderung pada bulan April September.

\section{UCAPAN TERIMA KASIH}

Ucapan terima kasih penulis tujukan kepada Prof. Dr. Sutrisno Anggoro, M.S. dan Bapak Agung F. Nugroho beserta staf kepegawaian Pelabuhan Perikanan Samudera (PPS) Cilacap, Jawa Tengah yang telah mengijinkan peneliti untuk melakukan penelitian;

\section{Daftar Pustaka}

Camhi, M. S. Fowler, J. Musick, A. Brautigam dan S. Fordham. 1998. The IUCN Species Survival Commission: Sharks and Their Relatives, Ecology and Conservation. Information Press, Oxford, UK, 63 p.

Candramila, W. dan Junardi. 2006. Komposisi, Keanekaragaman dan Rasio Kelamin Ikan Elasmobranchii Asal Sungai Kakap Kalimantan Barat. Biospecies, 1(2):41 - 46.

Dharmadi, Fahmi dan S. Triharyuni. 2012. Aspek Biologi dan Fluktuasi Hasil Tangkapan Cucut Tikusan, (Alopias Pelagicus) di Samudera Hindia. Bawal, 4(3):131 - 139.

Effendie,M. I. 1979. Metoda Biologi Perikanan.Yayasan Dewi Sri. Bogor. 112 p.

. 2002. Biologi Perikanan. Yayasan Pustaka Nusatama, Yogyakarta, 163 hlm.

Fahmi dan Dharmadi. 2013. Tinjauan Status Perikanan Hiu dan Upaya Konservasinya di Indonesia. Direktorat Konservasi Kawasan dan Jenis Ikan, Direktorat Jenderal Kelautan, Pesisir dan Pulau-Pulau Kecil, Kementerian Kelautan dan Perikanan. Jakarta, 179 hlm. 
Fernandez, C. J., R. Coelho, K. Erzini and M. N. Santos. 2011. Age and Growth of The Bigeye Thresher Shark, Alopias superciliosus, from The Pelagic Longline Fisheries in The Tropical Northeastern Atlantic Ocean, Determined by Vertebral Band Counts. Aquatic Living Resources, 24:359-368.

Froese, R. 2006. Cube Llaw, Condition Factor and Weight Length Relationship: History, Meta-Analysis and Recommendations. Journal of Applied Ichthyology, 22: 241-253.

Jennings, S, M. J. Kaiser, J. D. Reynolds. 2001. Marine Fishery Ecology. Blackwell Sciences, Oxford. 432 p.

Nasir, M. 1983. Metode Penelitian. Ghalia Indonesia, Jakarta, 622 hlm.

Preti, A., S. Kohin, H. Dewar and D. Ramon. 2008. Feeding Habits of The Bigeye Thresher Shark (Alopias Superciliosus) Sampled from The California-Based Drift Gillnet Fishery. CalCOFI Rep., 49.

Prihatingsih, B. Sadhotomo, dan M. Taufik. 2013. Dinamika Populasi Ikan Swanggi (Priacanthus tayenus) di Perairan Tangeran - Banten. Bawal 5(2):81 - 87.

Rochmatin, S.Y., A. Solichin dan S.W. Saputra. 2014. Aspek Pertumbuhan dan Reproduksi Ikan Nilem (Osteochilus hasselti) di Perairan Rawa Pening Kecamatan Tuntang Kabupaten Semarang. Diponegoro Journal of Maquares, 3(3):153 - 159.

Saputra, S.W. 2008. Biologi, Dinamika Populasi dan Pengelolaan Udang Metapenaeus elegans de Man 1907 di Laguna Segara Anakan Cilacap Jawa Tengah. Universitas Diponegoro, $161 \mathrm{hlm}$.

Saputra, S.W., P. Soedarsono, G.A. Sulistyawati. 2009. Beberapa Aspek Biologi Ikan Kuniran (Upeneus spp) di Perairan Demak. Jurnal Saintek Perikanan, 5(1):1 - 6.

Setiawan, I. dan A.F. Nugroho. 2015. Jenis dan Jumlah Tangkapan Hiu di Perairan Laut Selatan Jawa Tengah. Dalam: Prosiding Simposium Hiu dan Pari di Indonesia di IPB Convention Centre Bogor 10 Juni 2015. KKP dan WWF-Indonesia, pp. $9-13$.

Suryana. 2010. Metodologi Penelitian: Model Prakatis Penelitian Kuantitatif dan Kualitatif. Buku Ajar Perkuliahan. Universitas Pendidikan Indonesia, Bandung, $58 \mathrm{hlm}$.

Wahyuono, H., Budiharjo, S., Wudianto, Rustam, R. 1983. Pengamatan Parameter Biologi Beberapa Jenis Ikan Demersal di Perairan Selar Malaka Sumatera Utara. Laporan Penelitian Laut. Jakarta. 